\title{
Transformation of cyclic ketones as impurities in cyclohexanone in the caprolactam production process.
}

Author List: Lorenzo, $D^{\mathrm{a}}$.; Romero, $\mathrm{A}^{\mathrm{b}}$; Del-Arco, L.c; Santos, $\mathrm{A}^{\mathrm{d}}$

$(a, b, c, d)$ Chemical Engineering and Materials Department. Universidad Complutense de Madrid. Spain

(a) dlorenzo@quim.ucm.es

(b) aromeros@quim.ucm.es

(c) 1delarcopuente@gmail.com

(d) aursan@quim.ucm.es

${ }^{*}$ Corresponding Author

Keywords: 2-cyclohexen-1-one, n-methylcaprolactams, 2-methylcyclopentanone, oximation, Beckmann Rearrangement, caprolactam. 
Table S1. Chemical used.

\begin{tabular}{|c|c|c|c|c|c|c|c|}
\hline Compound & Use & & Ref. & $\begin{array}{l}\text { Purity. } \\
\text { (\%) }\end{array}$ & $\begin{array}{c}\text { MW } \\
(\mathrm{g} / \mathrm{mol})\end{array}$ & CAS & Scheme \\
\hline $\begin{array}{l}\text { 2-Cyclohexen-1-one } \\
\text { (CXENONE) }\end{array}$ & Reactant & $\begin{array}{l}\text { Sigma- } \\
\text { Aldrich }\end{array}$ & 92509 & 98 & 96 & $930-68-7$ & \\
\hline $\begin{array}{c}2- \\
\text { methylciclohexanone } \\
\text { (2-MEONE) }\end{array}$ & Reactant & $\begin{array}{l}\text { Sigma- } \\
\text { Aldrich }\end{array}$ & M38400 & 99 & 112 & $583-60-8$ & \\
\hline $\begin{array}{c}3- \\
\text { methylcyclohexanone } \\
\text { (3-MEONE) }\end{array}$ & Reactant & $\begin{array}{l}\text { Sigma- } \\
\text { Aldrich }\end{array}$ & M3860-5 & 97 & 112 & $591-24-2$ & \\
\hline $\begin{array}{c}\text { 4- } \\
\text { methylciclohexanone } \\
\text { (4-MEONE) }\end{array}$ & Reactant & $\begin{array}{l}\text { Sigma- } \\
\text { Aldrich }\end{array}$ & W394807 & $\geq 99$ & 112 & $589-92-4$ & \\
\hline $\begin{array}{c}2- \\
\text { methylcyclopentanone } \\
(2-\mathrm{MECPONE})\end{array}$ & Reactant & $\begin{array}{l}\text { Sigma- } \\
\text { Aldrich }\end{array}$ & 288438 & 98 & 98 & $1120-72-5$ & \\
\hline Sodium Hydroxide & $\begin{array}{l}\text { Reactant } \\
\text { Titration }\end{array}$ & $\begin{array}{l}\text { Sigma- } \\
\text { Aldrich }\end{array}$ & S5881 & $\geq 98$ & 40 & $1310-73-2$ & $\mathrm{NaOH}$ \\
\hline Nitrocyclohexane & ISTD & $\begin{array}{l}\text { Sigma- } \\
\text { Aldrich }\end{array}$ & N16606 & 97 & 129 & $1122-60-7$ & $\mathrm{C}_{6} \mathrm{H}_{11} \mathrm{NO}_{2}$ \\
\hline Ammoium solution & Reactant & Panreac & 211129 & 25 & 17 & $1336-21-6$ & $\mathrm{NH}_{3}$ \\
\hline $\begin{array}{l}\text { Hydroxylammonium } \\
\text { sulfate }\end{array}$ & Reactant & ACROS & A0388374 & 99 & 164 & $10039-54-0$ & $\left(\mathrm{HONH}_{3}\right)_{2} \mathrm{SO}_{4}$ \\
\hline Sulfuric acid & Reactant & ACROS & $\begin{array}{c}30207002 \\
6 \\
\end{array}$ & 96 & 98 & $7664-93-9$ & $\mathrm{H}_{2} \mathrm{SO}_{4}$ \\
\hline$\varepsilon$-caprolactam & Solvent & $\begin{array}{l}\text { Sigma- } \\
\text { Aldrich }\end{array}$ & $\mathrm{C} 2204$ & 99 & 113 & $105-60-2$ & \\
\hline
\end{tabular}




\section{GC/MSD and NMR spectra of pure oximes systethyzed from cyclic ketones.}

In Figure S1 total ion chromatogram of a mixture of $10000 \mathrm{mg} \cdot \mathrm{kg}^{-1}$ of pure oximes of 2methylcyclopentanone, cyclohexanone, 2-methylcyclohexanone, 3-methylcyclohexanone and 2cyclohexen-1-one diluted in 1-butanol is shown. In Figure S2 to Figure S6, the experimental mass spectra of the oximes, which were synthetized from pure cyclic ketones, are provided. The assignation was carried out analysing the pure oximes individually. Moreover, some of them were compared with the available spectra on NIST library and Wiley Database in Scifinder.

In Figure S7 to Figure S11, the 1H-NMR spectra of the stereoisomer mixture are provided. These were used to identify the stereoisomers formed in the oximation reaction and mass ratio between them. The identification of stereoisomers was accomplished as follows:

2-methylcyclopentanone oxime (Figure S7): The signal used was the doublet of the methyl group $\mathrm{CH} 3$ (bonded to carbon 2 in cyclic chain). This group is close to the oxime functional group $(\mathrm{C}=\mathrm{N}-$ $\mathrm{OH}$ ), and the deshielding of the protons of the cis isomers is greater because of oxygen electronegativity. For this reason, the doublet of the cis isomers presents a higher chemical shift (1.20-1.14 ppm) than the trans isomer. The ratio between this isomer was found using the integral of the doublet signals as 9:91\% for cis and trans stereoisomers respectively.

2-methylcyclohexanone oxime (Figure S8): Both isomers can be identified using the doublet signals at chemical shift $\delta 1.09-1.12(\mathrm{~J}=7.2 \mathrm{~Hz})$ and $1.11-1.13(\mathrm{~J}=6.6 \mathrm{~Hz})$. These signals are produced by the methyl group at position 2 in the cyclic carbon chain, close to the $\mathrm{C}=\mathrm{N}-\mathrm{OH}$. The doublet signal with the highest chemical shift is due to the cis $(Z)$ isomer. The deshielding of the protons is greater due to the oxygen effect. The area integral intensity ratio between the formed stereoisomers was found to be $13 \%$ and $87 \%$ for cis and trans isomers respectively. This ratio was confirmed by the signal from by the hydrogen atom that compounds the group $\mathrm{CH}$ (positions 2 in the carbon cyclic chain). The signal is a multiplet with a chemical shift at $\delta 3.2-3.1 \mathrm{ppm}$. This corresponds with the isomer cis while the second multiplet at $\delta 3.6-3.5 \mathrm{ppm}$ is generated by the $Z$ isomer.

3-methylcyclohexanone oxime (Figure S9): The ratio between trans/cis isomers was established by studying the integration area of the signals produced by the doublets at $0.99-0.95 \mathrm{ppm}$ and $1.04-$ 
0.99. The highest chemical shift is due to the oxygen effect over the cis isomer. In this group, the oxygen of the oxime functional group of the cis $(Z)$ isomer has a greater effect on the electron density, and the doublet signal of this proton has a higher chemical shift $(\delta 1.04 \mathrm{ppm})$ than the same group of the trans $(\mathrm{E})$ isomer $(\delta 0.95 \mathrm{ppm})$. The ratio can thus be established as $52 \%$ for the trans isomer and $48 \%$ for the cis isomer.

4-methylcyclohexanone oxime (Figure S10): Only one isomer is identified because this ketone is symmetric.

2-cyclohexen-1-one oxime (Figure S11): the NMR spectrum presents a doublet generated by the hydrogen atom that conforms the $\mathrm{CH}$ group located in position 2 of the carbon cyclic chain. This $\mathrm{CH}$ is close to the oxime functional group and the effect of the oxygen is the key to distinguishing the stereoisomers and their mass ratio. As explained above in the other cyclic oximes, the deshielding of the cis isomer is greater than the for the same group in the trans isomer. For this reason, the doublet of $\mathrm{CH}$ of the cis isomer has a higher chemical shift $(\delta 6.82)$ than the trans isomer $(\delta 6,14)$. Moreover, the oxygen atom of the group $\mathrm{C}=\mathrm{N}-\mathrm{OH}$ also affects the hydrogens of the $\mathrm{CH} 2$ in position 6 . These signals are triplets, but the oxygen atom affects the $\mathrm{CH} 2$ group of the trans isomer more than the cis isomer. The triplet of the trans isomer thus has a higher chemical shift $(\delta 2.65)$ than the cis isomer $(\delta 2.42)$. The area integral intensity ratio of isomer production when the 2-cyclohexen-1-one is obtained was found to be $27 \%$ and $73 \%$ for cis and trans isomers respectively. 


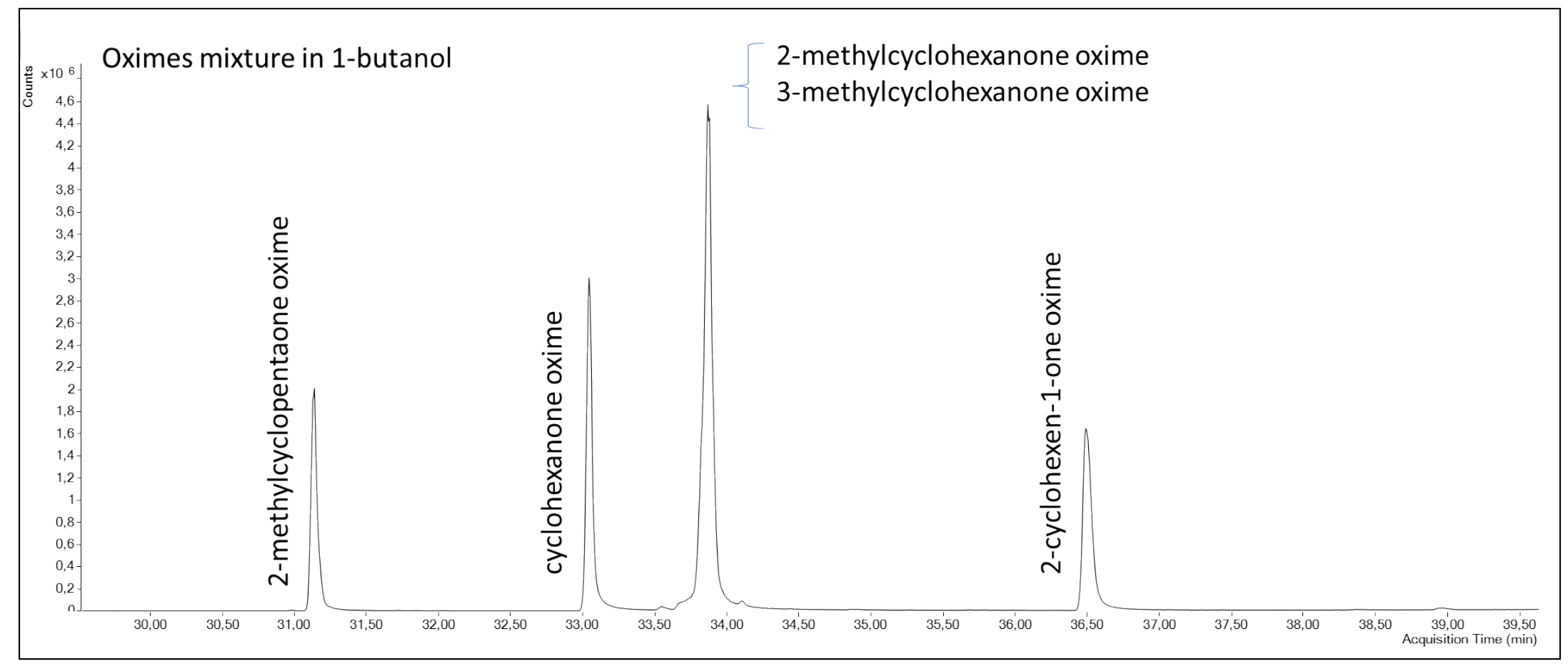

Figure S1. Total ion chromatogram (TIC) of $10000 \mathrm{mg}$ of each pure oxime mixture in $1 \mathrm{~kg}$ of 1-butanol using nitro cyclohexane (25.43 min) as ISTD 


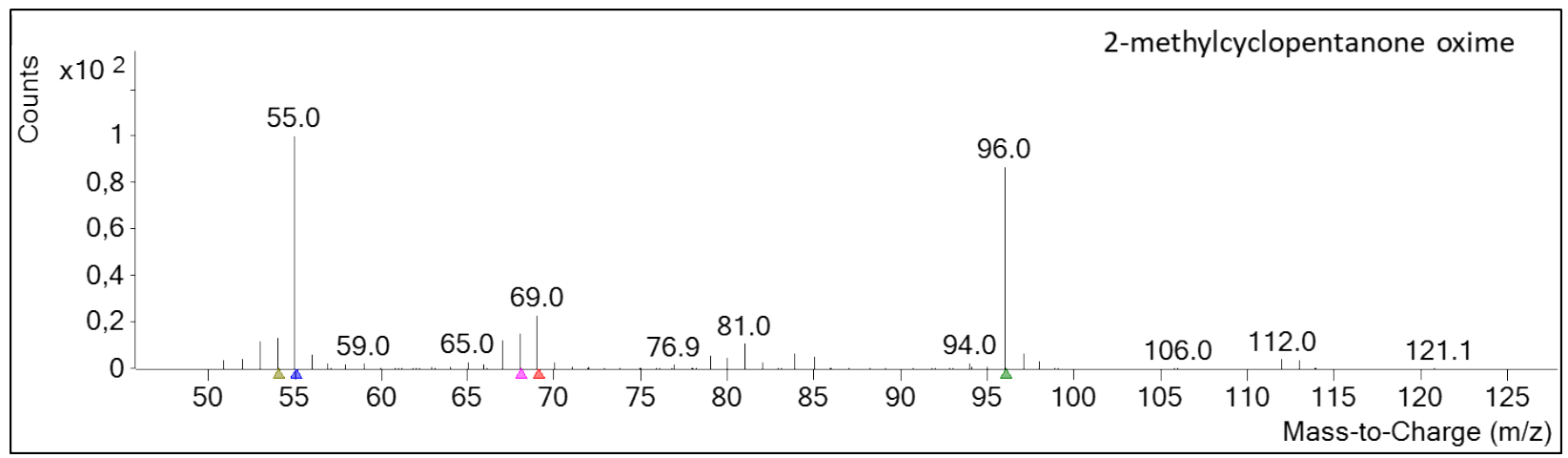

Figure S2. Mass spectra of 2-methylcyclopentanone oxime obtained from the analysis of the pure synthetized compound.

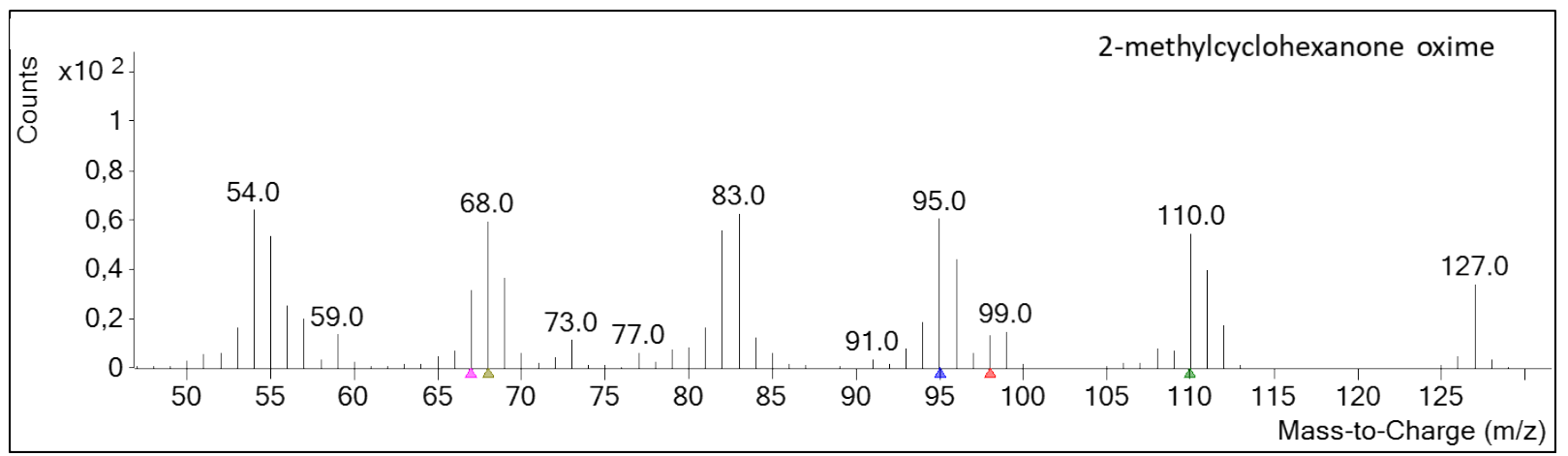

Figure S3. Mass spectra of 2-methylcyclohexanone oxime obtained from the analysis of the pure synthetized compound, identified using NIST database (Version 011) (Babushok et al., 2007).

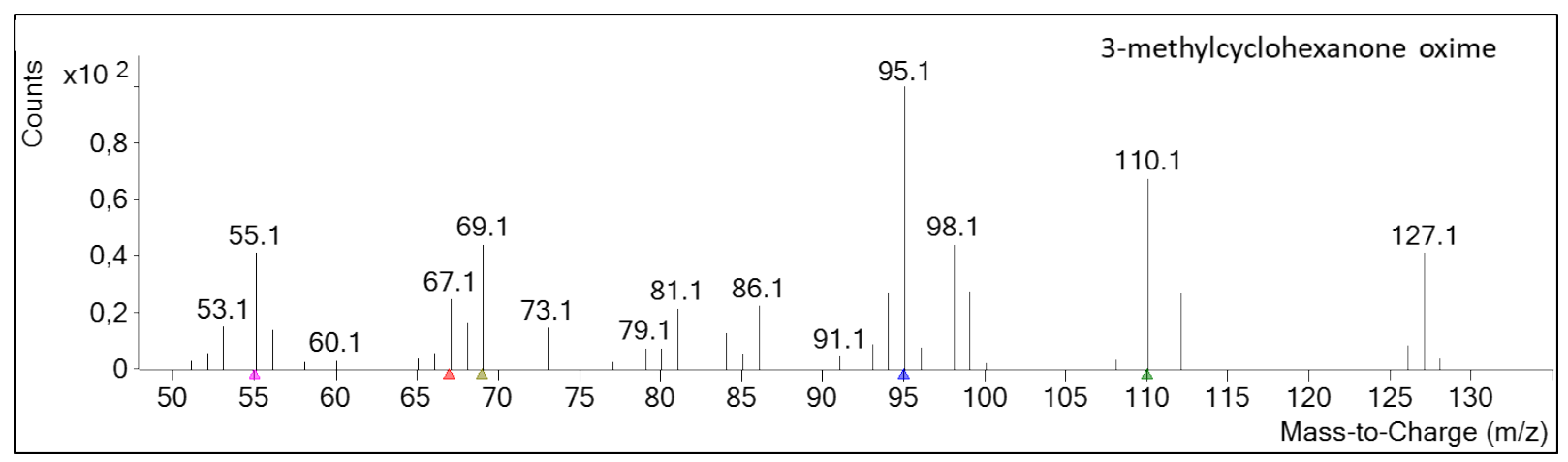

Figure S4. Mass spectra of 3-methylcyclohexanone oxime obtained from the analysis of the pure synthetized compound. It was also identified using SciFinder Database spectra (WSS ID: ID_WID-DLO-005081-7). 


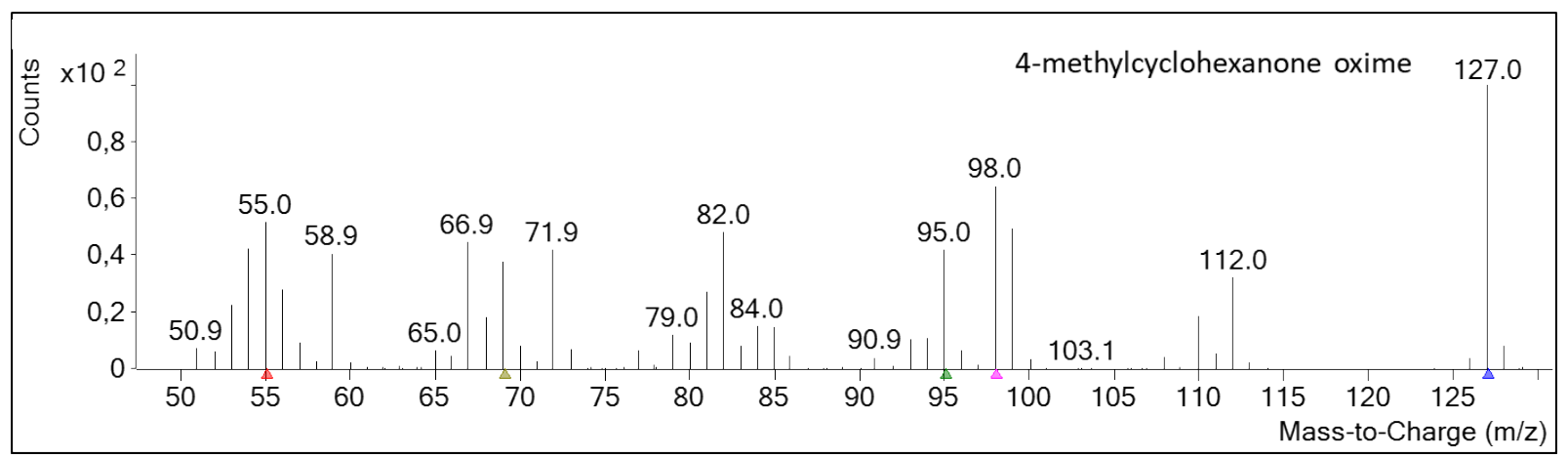

Figure S5. Mass spectra of 4-methylcyclohexanone oxime obtained from the analysis of the pure synthetized compound. It was also identified using SciFinder Database spectra (WSS ID: ID_WID-DLO-005102-5).

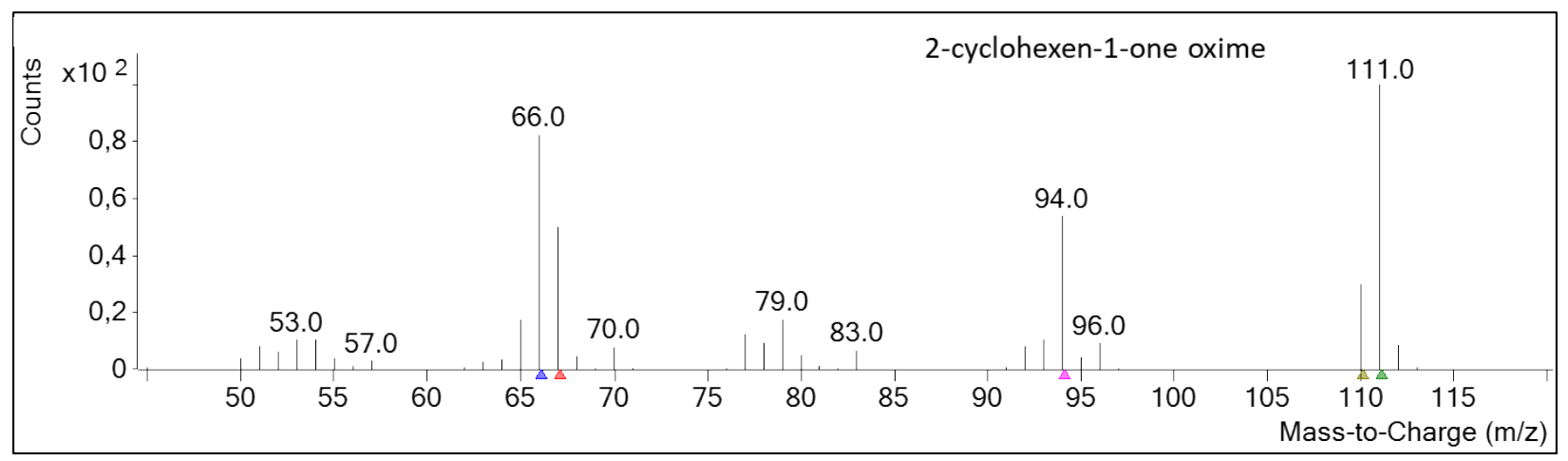

Figure S6. Mass spectra of 2-cyclohexen-1-one oxime obtained from the analysis of the pure synthetized compound, identified using the NIST database (Version 011) (Babushok et al., 2007). 


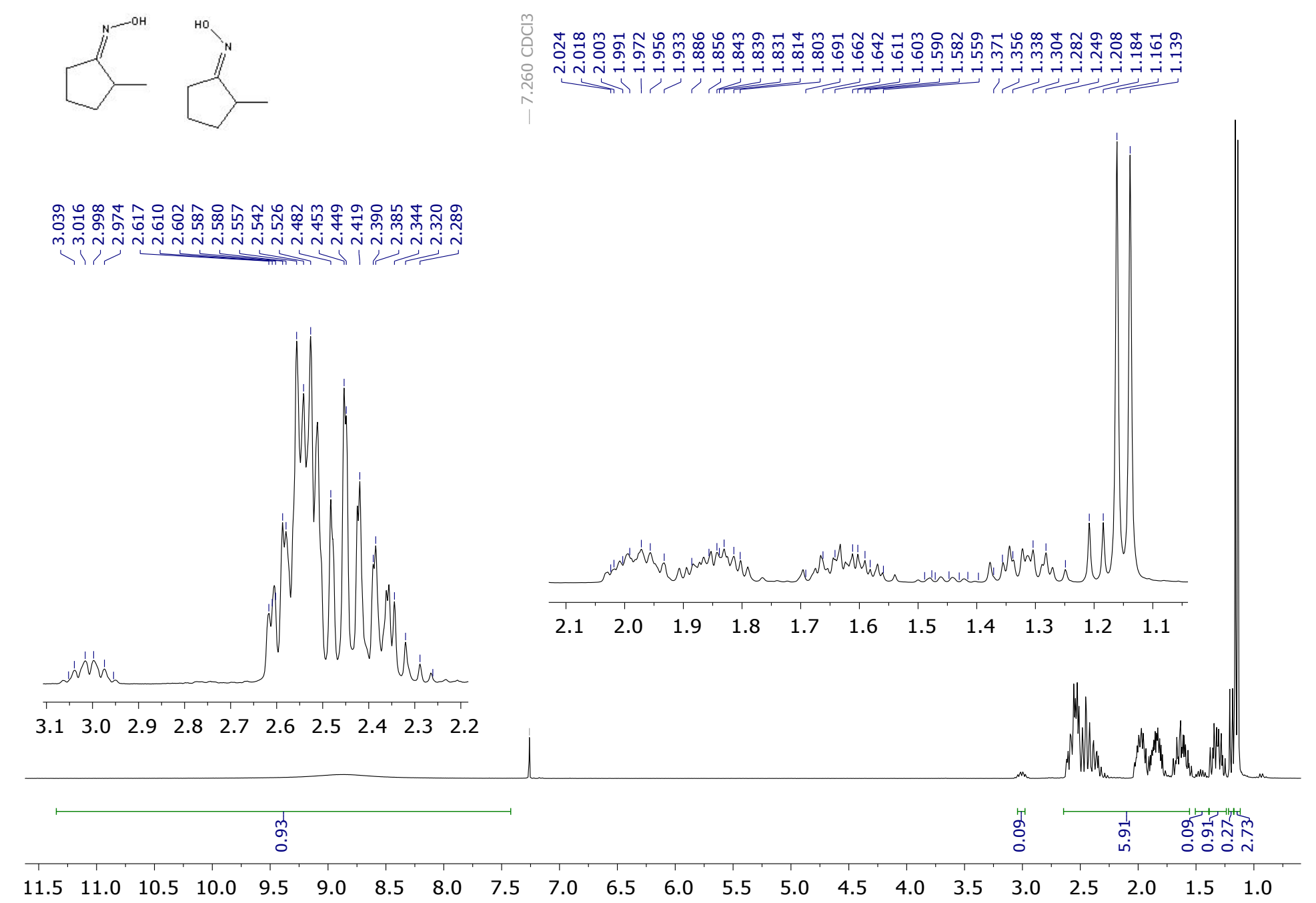

Figure S7. (1E)-2-methylcyclopentanone oxime: ${ }^{1} \mathrm{H}-\mathrm{RMN}(300 \mathrm{MHz}, \mathrm{CDCl}): \delta$ 2.65-1.55 (m, 6H, $\left.\mathrm{CH}_{2}\right), 1.41-1.26$ (m, $\left.1 \mathrm{H}, \mathrm{CH}\right), 1.20-1.14(\mathrm{~d}, J$ $\left.=6.7 \mathrm{~Hz}, 3 \mathrm{H}, \mathrm{CH}_{3}\right) .(1 \mathrm{Z})-2$-methylcyclopentanone oxime: ${ }^{1} \mathrm{H}-\mathrm{RMN}(300 \mathrm{MHz}, \mathrm{CDCl} 3): \delta 3.1-2.9(\mathrm{~m}, 1 \mathrm{H}, \mathrm{CH}), 2.65-1.55(\mathrm{~m}, 5 \mathrm{H}, \mathrm{CH}), 1.55$ $1.40\left(\mathrm{~m}, 1 \mathrm{H}, \mathrm{CH}_{2}\right), 1.24-1.20\left(\mathrm{~d}, J=7.1 \mathrm{~Hz}, 3 \mathrm{H}, \mathrm{CH}_{3}\right)$. 

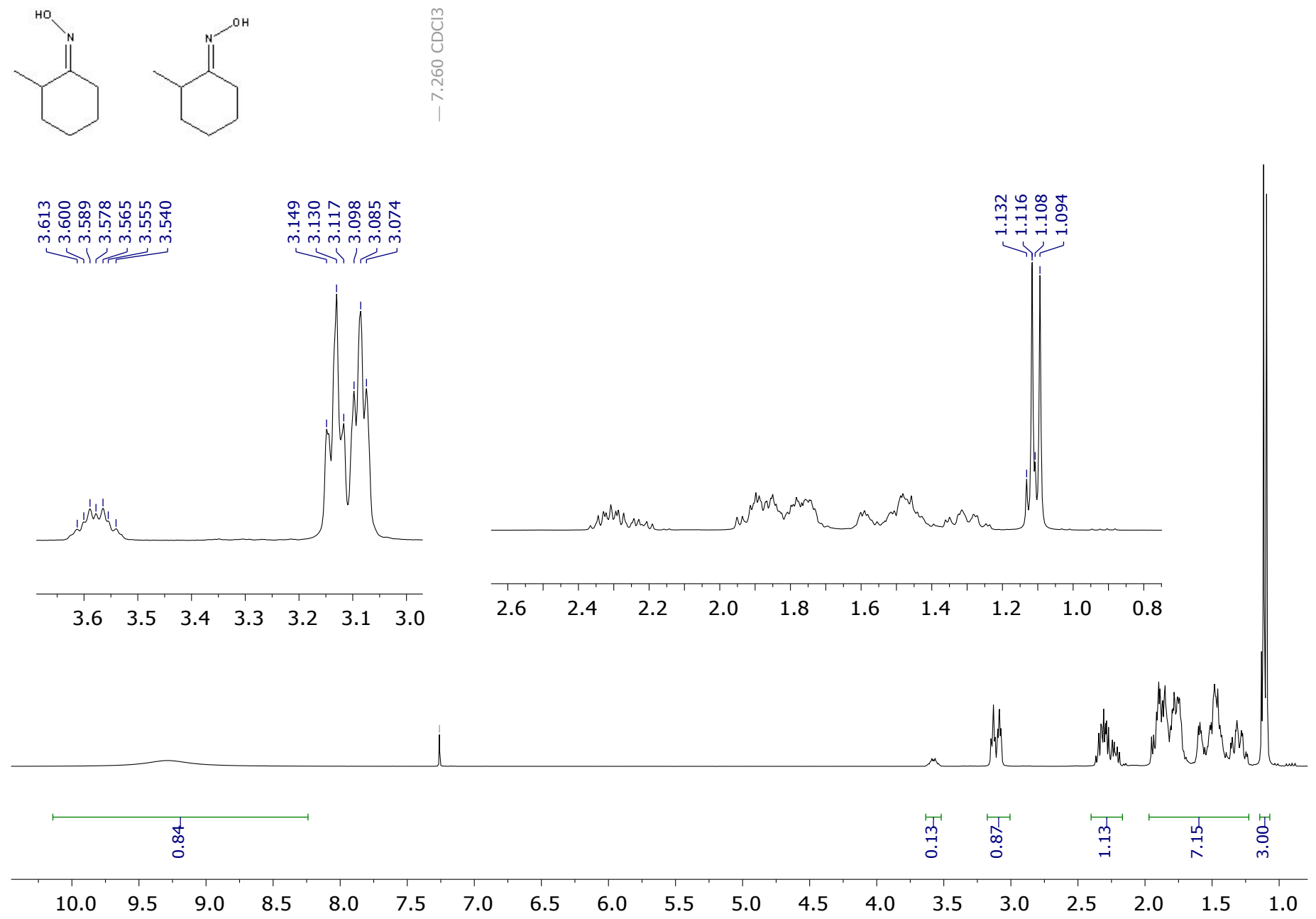

Figure S8. (1Z)-2-methylcyclohexanone oxime: 1H-RMN (300MHz, CDCl3): $\delta 3.67-3.54$ (dt, 2H CH2), 2.00-1.2 (m, 6H, 3CH2), 2.4-2.2 (m, 1H. $\mathrm{CH}), 1.14-1.12(\mathrm{~d}, \mathrm{~J}=7.2 \mathrm{~Hz}, 3 \mathrm{H}, \mathrm{CH} 3)$. (1E)-2-methylcyclohexanone oxime: 1H-RMN (300MHz, CDCl3): $\delta 3.21-3.07$ (dt, $2 \mathrm{H}, \mathrm{CH} 2), 2.00-1.2$ (m, 6H, 3CH2), 2.4-2.2 (m, 1H. CH), 1.14-1.12 (d, J = 6.6Hz, 3H, CH3). 


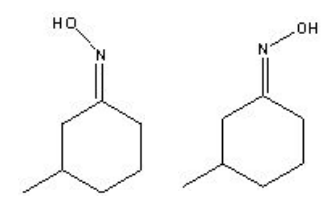

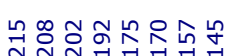

הู่

mmmminm

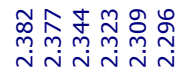

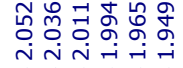

तो

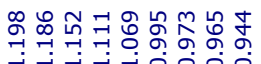

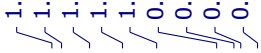
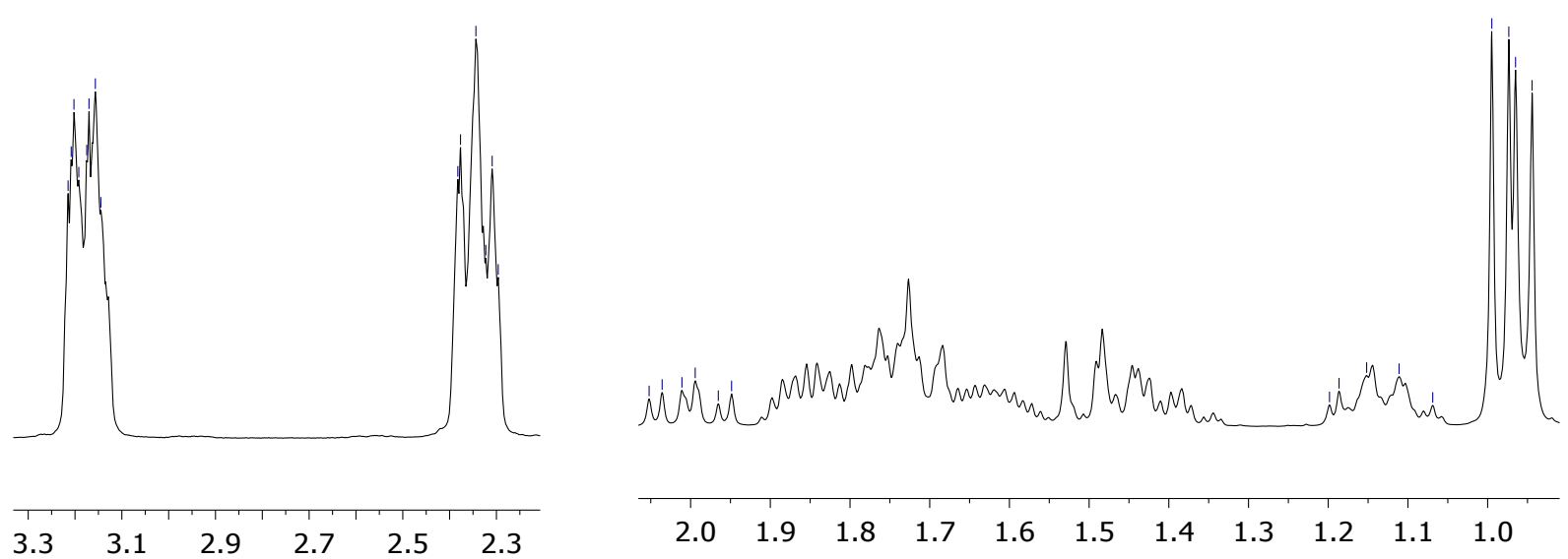

$\begin{array}{lll}2.0 & 1.9 & 1.8\end{array}$

$\begin{array}{llll}1.7 & 1.6 & 1.5 & 1.4\end{array}$
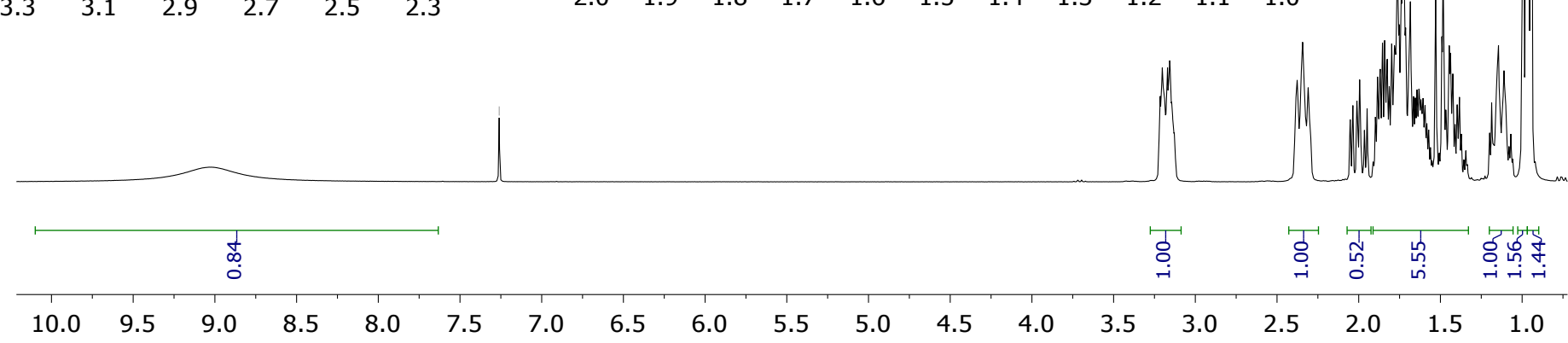

Figure S9. (1E)-3-methylcyclohexanone oxime: 1H-RMN (300MHz, CDCl3): $\delta 3.3-3.1(\mathrm{~m}, 1 \mathrm{H}, \mathrm{CH} 2), 2.55-2.3$ (m, 1H, CH2), $1.95-1.1(\mathrm{~m}, 7 \mathrm{H}$, $3 \mathrm{CH} 2, \mathrm{CH})$ 0.99-0.95 (d, J = 6.24Hz, 3H, CH3). (1Z)-3-methylcyclohexanone oxime: 1H-RMN (300MHz, CDCl3): $\delta 3.3-3.1$ (m, 1H, CH2), 2.552.3 (m, 1H, CH2), 2.10-1.95 (m, 1H, CH), 1.95-1.1 (m, 6H, 3CH2), 1.04-0.99 (d, J =6.39Hz, 3H, CH3). 


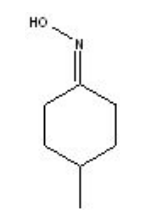

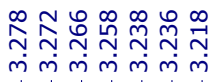

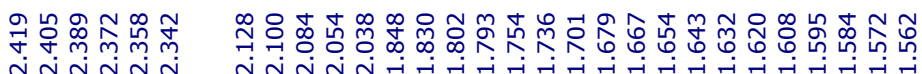
$\sqrt{1 / 1 / 3 \pi}$ Ninj

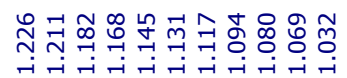

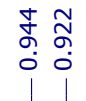
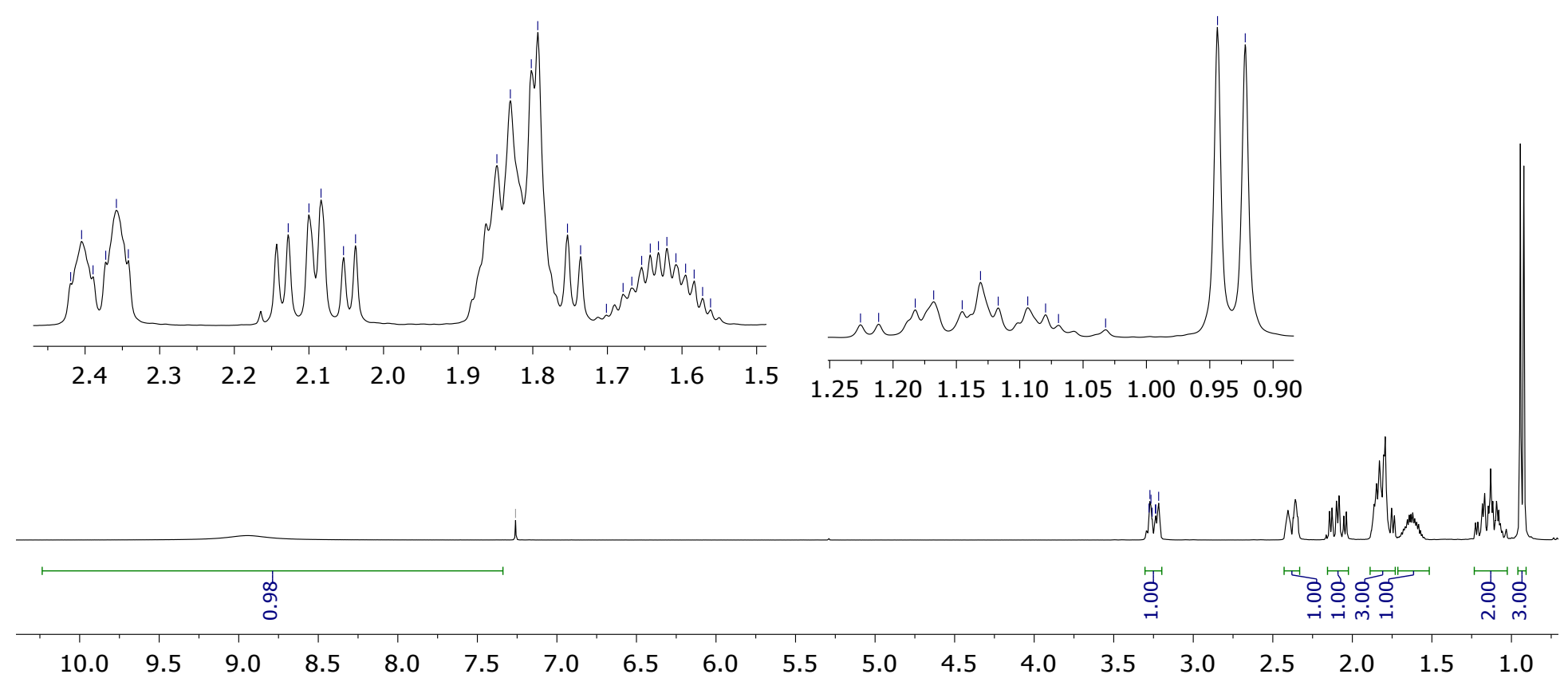

Figure S10. 4-methylcyclohexanone oxime: 1H-RMN (300MHz, CDCl3): $\delta 3.35-3.20(\mathrm{~m}, 1 \mathrm{H}), 2.45-2.35(\mathrm{dt}, \mathrm{J}=4.4 \mathrm{~Hz}, 1 \mathrm{H}), 2.17-2.05(\mathrm{~m}, 1 \mathrm{H})$, $1.90-1.75(\mathrm{~m}, 3 \mathrm{H}), 1.75-1.57(\mathrm{~m}, 1 \mathrm{H}, \mathrm{CH}), 1.25-1.05(\mathrm{~m}, 2 \mathrm{H}), 0.98-0.93(\mathrm{~d}, \mathrm{~J}=6.57 \mathrm{~Hz}, 3 \mathrm{H}, \mathrm{CH} 3)$. 


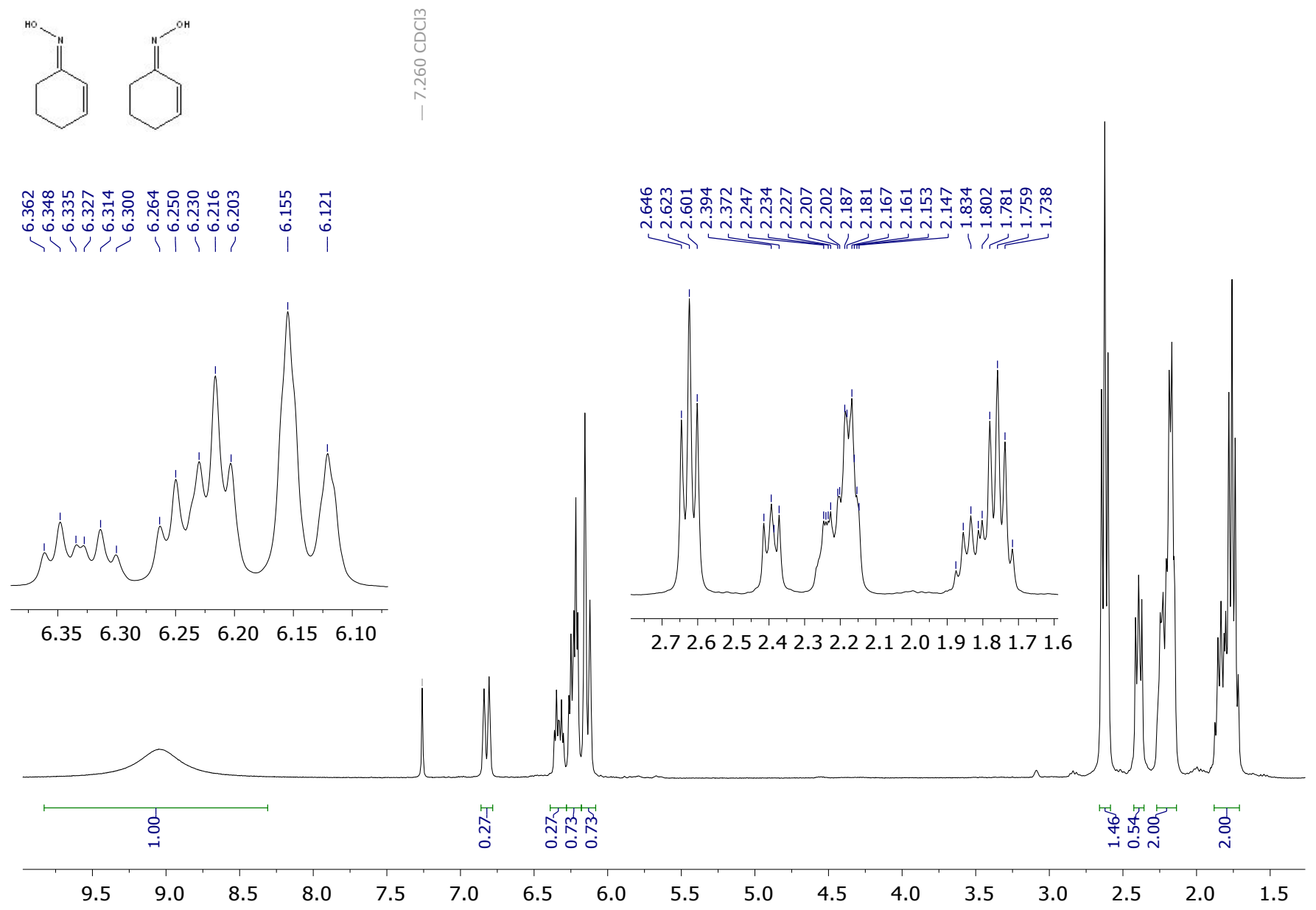

Figure S11. (1E)-2-Cyclohexen-1-ona oxime: 1H-RMN (300MHz, CDCl3): $\delta 1.82(\mathrm{~m}, 2 \mathrm{H}), 2.21(\mathrm{~m}, 2 \mathrm{H}), 2.65(\mathrm{t}, J=6.65 \mathrm{~Hz}, 2 \mathrm{H}), 6.16(\mathrm{~d}, J=$ $10.1 \mathrm{~Hz}, 1 \mathrm{H}), 6.26(\mathrm{dt}, \mathrm{Jab}=10.24 \mathrm{~Hz}, \mathrm{Jbc}=4.07 \mathrm{~Hz}, \mathrm{Jcd}=4.07 \mathrm{~Hz}) .(1 \mathrm{Z})-2$-cyclohexen-1-ona oxime: $1 \mathrm{H}-\mathrm{RMN}(300 \mathrm{MHz}, \mathrm{CDCl} 3): \delta 1.82(\mathrm{~m}$, $2 \mathrm{H}), 2.21(\mathrm{~m}, 2 \mathrm{H}), 2.42(\mathrm{t}, J=6.42 \mathrm{~Hz}, 2 \mathrm{H}), 6.85(\mathrm{~d}, J=10.27 \mathrm{~Hz}, 1 \mathrm{H}), 6.36(\mathrm{dt}, \mathrm{Jab}=10.28 \mathrm{~Hz}, \mathrm{Jbc}=4.05 \mathrm{~Hz}, \mathrm{Jcd}=4.05 \mathrm{~Hz}, 1 \mathrm{H})$. 


\section{GC/MSD spectra of amides from BR of pure cyclic oximes}

The detected chromatogram peaks are summarized in Table S2. They were identified by comparing the experimental mass spectra with that provided by the NIST library (Babushok et al., 2007) and/or the Wiley Service.

Table S2. Amides and precursor isomer oxime. Retention time (RT) Target ion and qualifiers (QF1 and QF2) are also summarized

\begin{tabular}{|c|c|c|c|c|c|}
\hline Amide & Precursor & $\begin{array}{l}\mathrm{RT} \\
\min \end{array}$ & Target & QF1 & QF2 \\
\hline 6-methyl-2-piperidone & (E)2-cyclopentanone oxime & 38.37 & 113 & 68 & 98 \\
\hline 3-methyl-2-piperidone & (Z)2-cyclopentanone oxime & 38.50 & 98 & 113 & 58 \\
\hline 7-methylcaprolactam & (E)2-methylcyclohexanone oxime & 38.74 & 127 & 112 & 85 \\
\hline 3-methylcaprolactam & (Z)2-methylcyclohexanone oxime & 38.99 & 114 & 87 & 143 \\
\hline 6-methylcaprolactam & (E)3-methylcyclohexanone oxime & 41.47 & 127 & 98 & 69 \\
\hline 4-methylcaprolactam & (Z)3-methylcyclohexanone oxime & 41.59 & 127 & 69 & 56 \\
\hline 5-methylcaprolactam & 4-methylcyclohexanone oxime & 41.89 & 127 & 99 & 69 \\
\hline $\begin{array}{l}\text { 1,5,6,7-tetrahydro-2H- } \\
\text { azepin-2-one }\end{array}$ & (Z)2-cyclohexen-1-one oxime & 43.95 & 111 & 83 & 59 \\
\hline
\end{tabular}




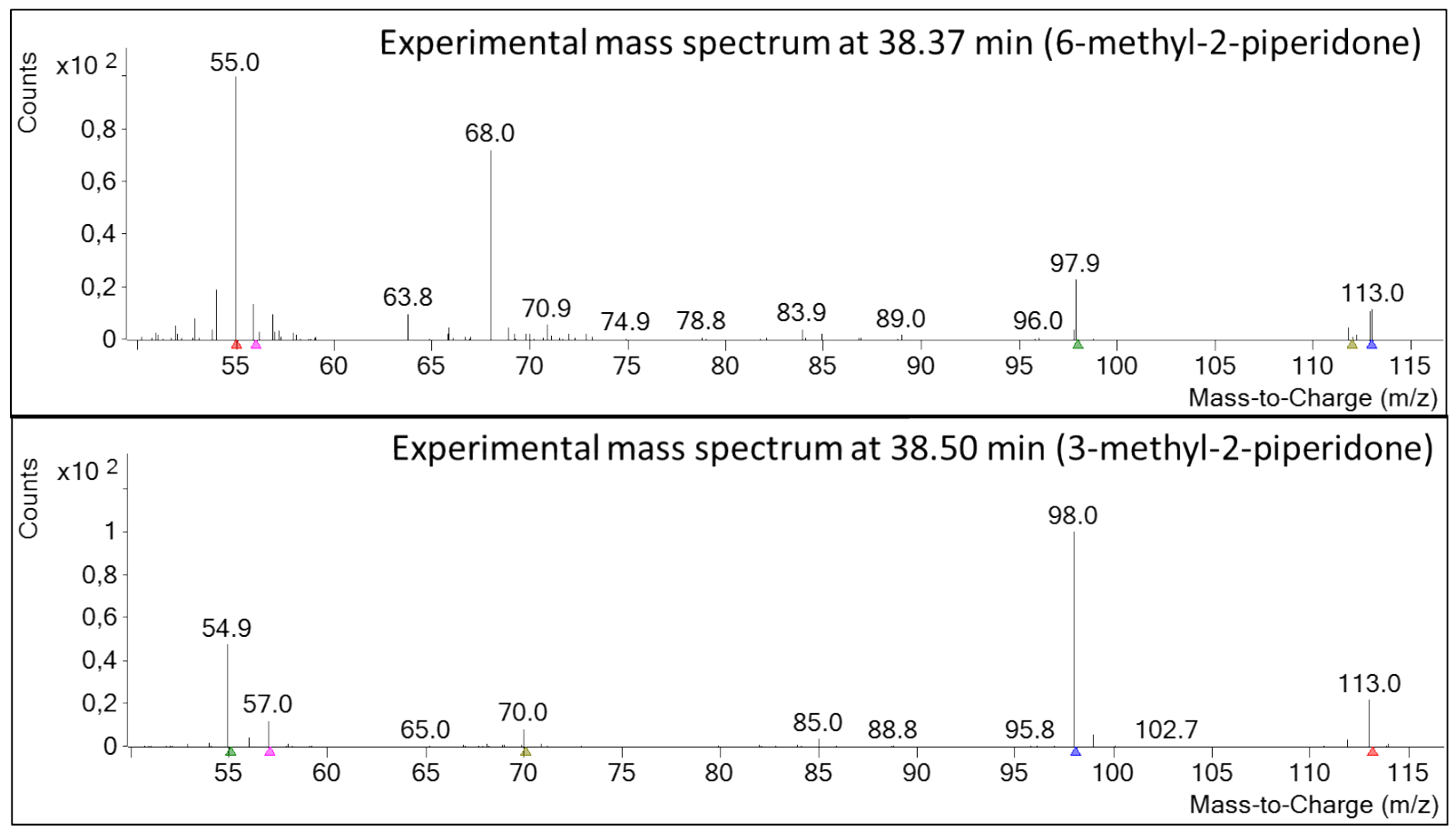

Figure S12. Experimental spectra obtained by GC/MS and SPME of the reaction mixture after Beckmann Rearrangement of the 2-methylcyclopentanone oxime (mixture of stereoisomers). The mass spectrum of 6-methyl-2-piperidone was provided by Wiley Database in Scifinder (ID: ID_WID-DLO-003039-7). 

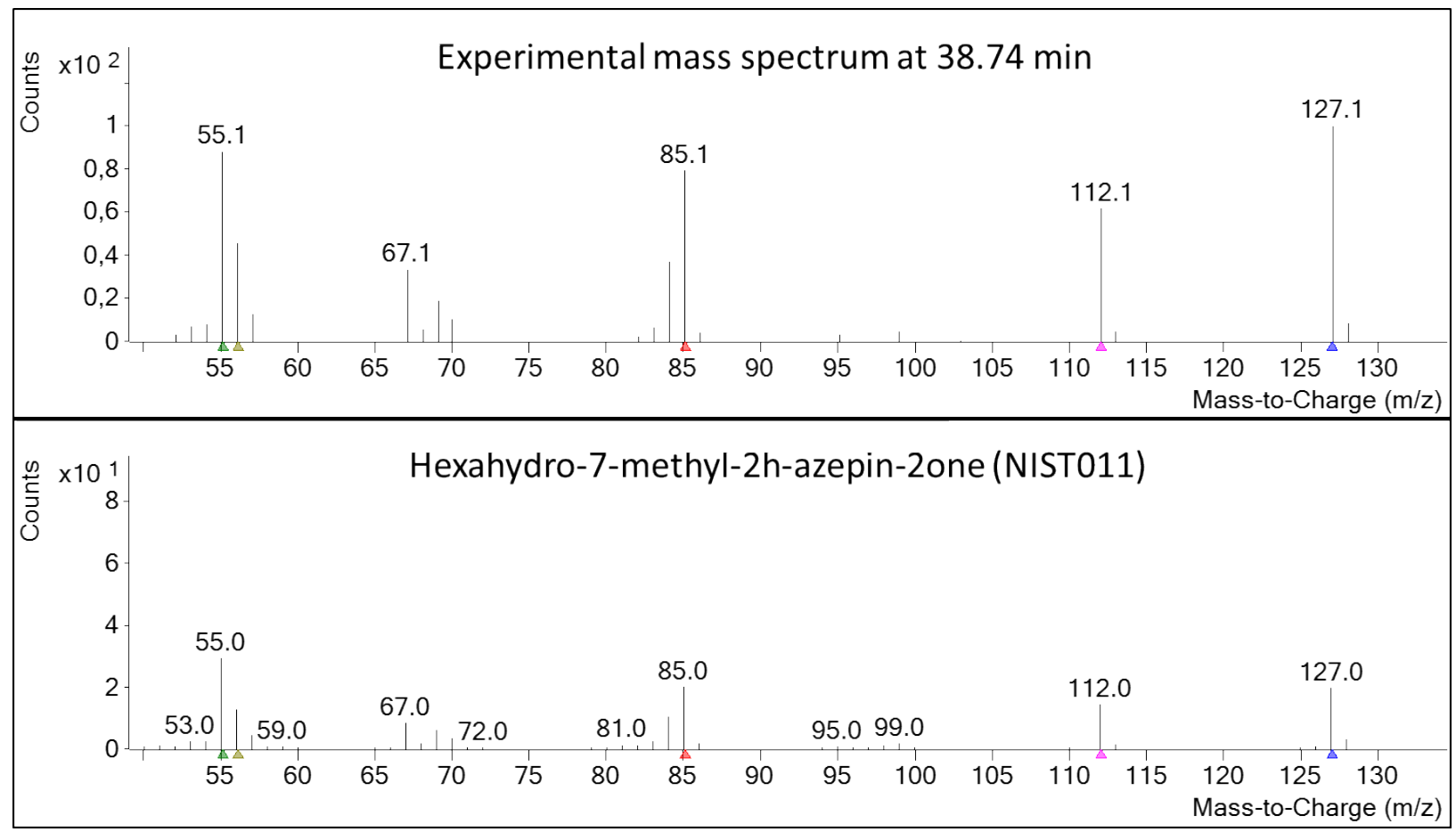

Figure S13. Experimental spectrum obtained by GC/MS and SPME of Beckmann Rearrangement of the (E)-2-methylcyclohexanone oxime. The experimental spectrum was identified using the spectrum provided NIST database (Version 011) (Babushok et al., 2007). 

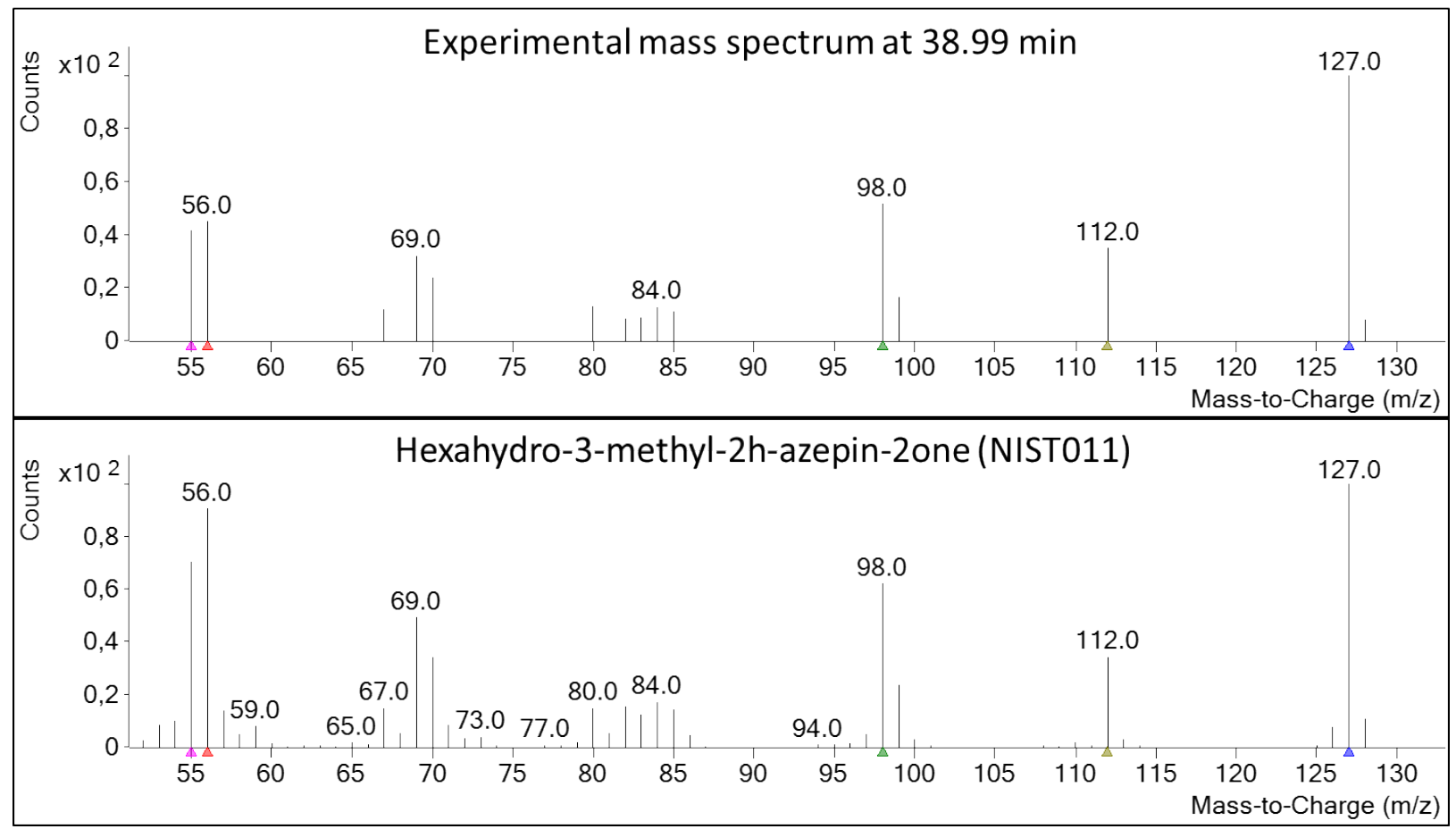

Figure S14. Experimental spectrum obtained by GC/MS and SPME of Beckmann Rearrangement of the (Z)-2-methylcyclohexanone oxime. The experimental spectrum was identified using the spectrum provided NIST database (Version 011) (Babushok et al., 2007). 


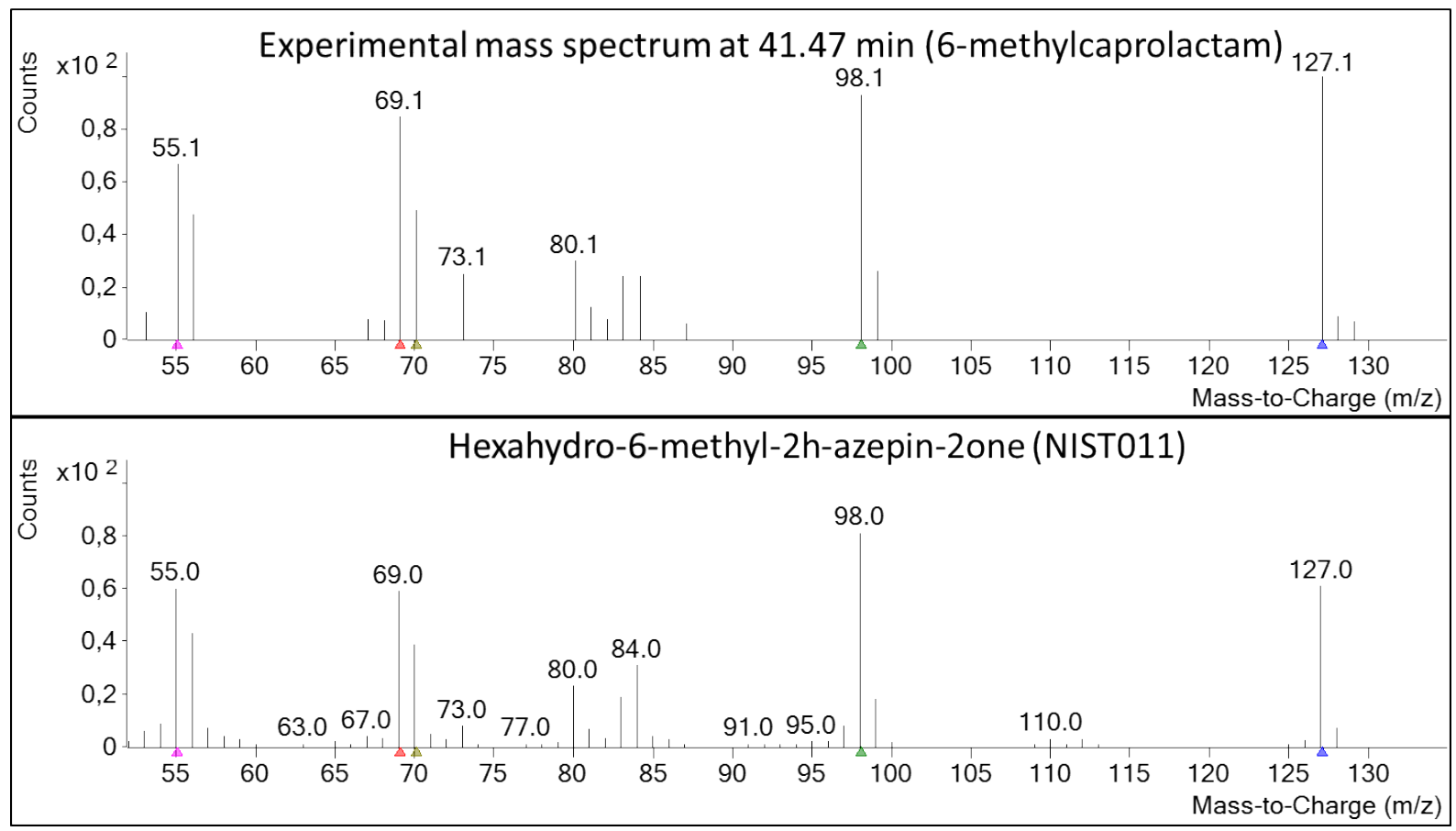

Figure S15. Experimental spectra obtained by GC/MS and SPME of the reaction mixture after Beckmann Rearrangement of the (E)-3-methylcyclohexanone oxime The experimental spectrum was identified using the spectrum provided NIST database (Version 011) (Babushok et al., 2007). 


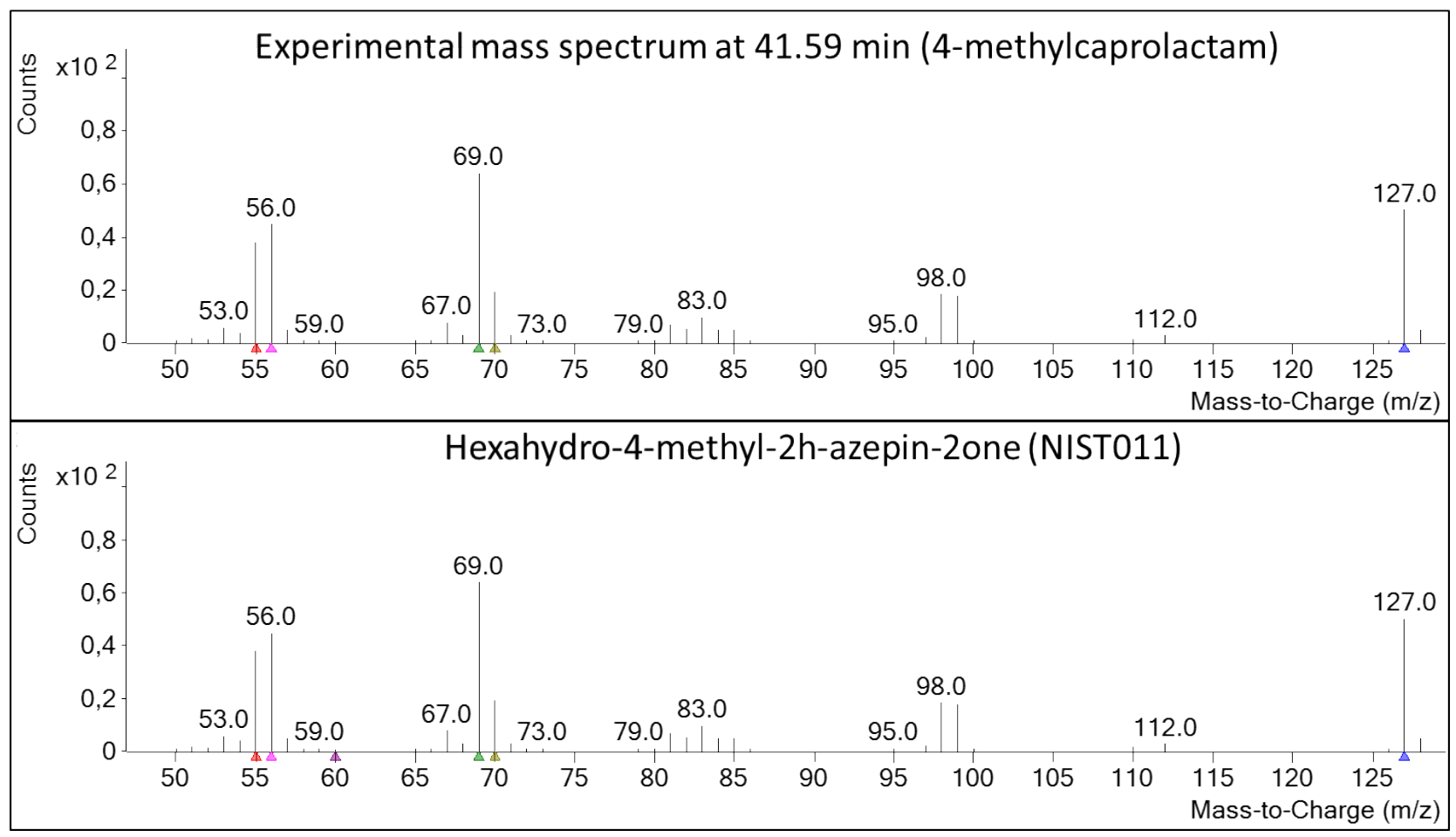

Figure S16. Experimental spectra obtained by GC/MS and SPME of the reaction mixture after Beckmann Rearrangement of the (Z)-3-methylcyclohexanone oxime The experimental spectrum was identified using the spectrum provided NIST database (Version 011) (Babushok et al., 2007). 


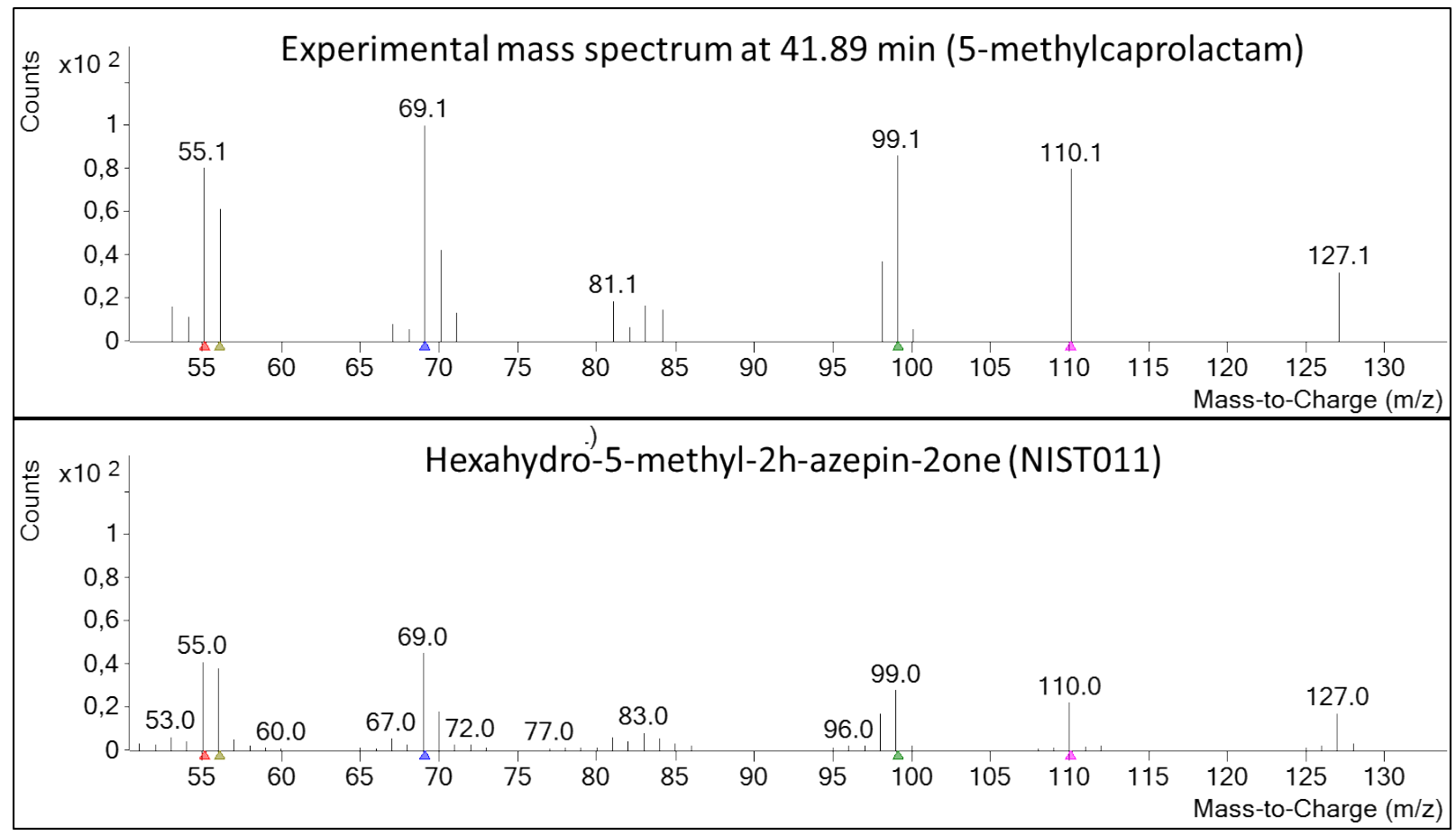

Figure S17. Experimental spectra obtained by GC/MS and SPME of the reaction mixture after Beckmann Rearrangement of the 4-methylcyclohexanone oxime The experimental spectrum was identified using the spectrum provided NIST database (Version 011) (Babushok et al., 2007).

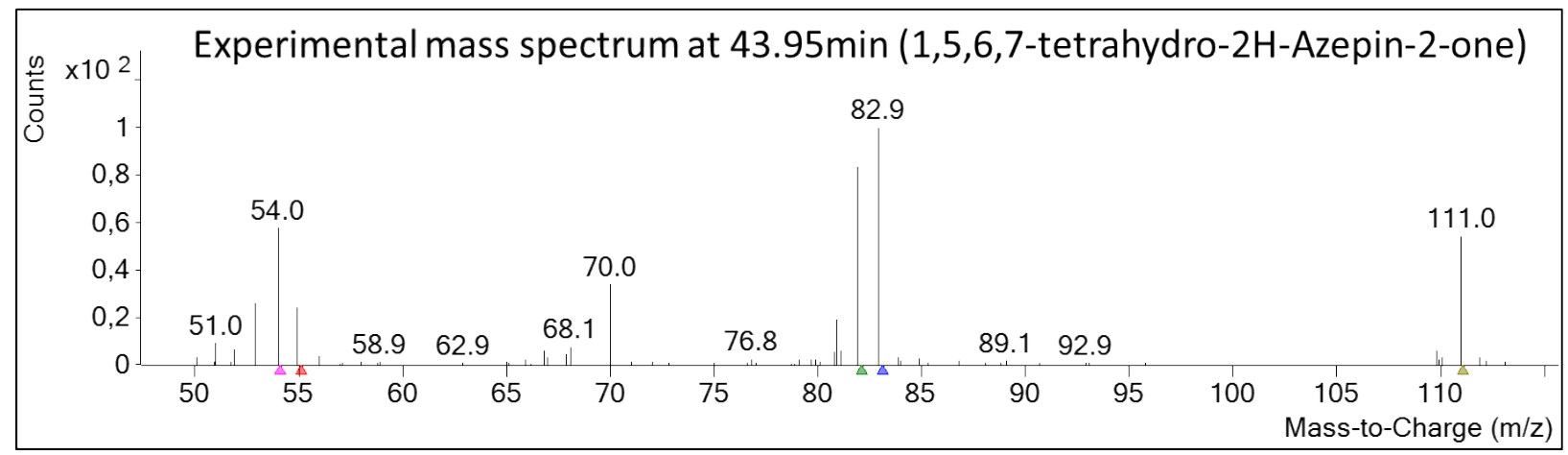

Figure S18. Experimental spectra obtained by GC/MS and SPME of Beckmann Rearrangement of the (Z)-2-cyclohexen-1-one oxime (mixture of stereoisomers). The mass spectrum of 1,5,6,7tetrahydro-2H-azepin-2-one was provided by Wiley Database (ID: CAS2009_1_011825). 


\section{References}

Babushok, V.I., Linstrom, P.J., Reed, J.J., Zenkevich, I.G., Brown, R.L., Mallard, W.G., Stein, S.E., 2007. Development of a database of gas chromatographic retention properties of organic compounds. Journal of Chromatography A 1157, 414-421. 